\title{
Postoperative functional status in patients with supratentorial superficial low-grade glioma
}

\author{
Ji Zhang ${ }^{1 \dagger}$, Yin sheng Chen ${ }^{1 \dagger}$, You-ping $\mathrm{Li}^{2 \dagger}$, Zheng-quan $\mathrm{Zhu}^{3+}$, Jian-min Liu ${ }^{4 \dagger}$, Cheng-cheng Guo ${ }^{1 \dagger}$, \\ Qun-ying Yang ${ }^{1}$, Xiao-li Wang ${ }^{5}$, Ying-hua Rao ${ }^{6}$, Qing Mao ${ }^{7}$, Wen-yan $\mathrm{Li}^{8}$, Lu Ma ${ }^{7}$, Yun qiang Yang ${ }^{9^{*}}$ \\ and Shi-yin Xiao ${ }^{10^{*}}$
}

\begin{abstract}
Background: We investigated the functional status of adult supratentorial superficial low-grade glioma (ASS-LGG) after surgery and analyzed its relevant factors to guide the therapeutic strategy and improve the life quality of these patients.

Methods: Clinical materials from January 2008 to December 2010 in 104 adults with ASS-LGG were analyzed retrospectively. The follow-up period ranged from 6 months to 1.5 years. The logistic regression was used to evaluate the preoperative and postoperative variation of functional status in patients to disclose the relevant factors affecting postoperative functional status, such as age, gender, the duration of symptom, size and location of the tumor, hemisphere, resection degree, and tumor pathologic grade and preoperative Karnofsky performance status (Pre-KPS).

Results: Four out of nine candidate factors are related to the postoperative functional status. They are age less than 40 years, the size of tumor less than $5 \mathrm{~cm}$ in diameter, tumor located in the right hemisphere, and limited resection of tumor in the eloquent area.
\end{abstract}

Conclusions: It seems more meaningful to evaluate the functional status of the patients with ASS-LGG on the basis of these clinical features, involving age, tumor size, location, and extent of resection.

Keywords: Functional status, ASS-LGG, Surgical therapy, Relative factor

\section{Background}

Low-grade glioma (LGG) accounts for more than $15 \%$ of adult gliomas and $25 \%$ of child gliomas [1]. The principle of surgery for LGG is to maximally protect the brain function and resect the tumor as much as possible $[2,3]$, but it seems difficult to reach a balance between resection degree and function protection because of no clear boundary between tumor and normal brain tissue. Thus, radical surgery versus functional protection is still a matter of debate in LGG patients [1,3]. The Karnofsky performance status (KPS), which is usually used for making clinical decisions, measures the variation in

\footnotetext{
*Correspondence: yangyun720@163.com; xsy8110@163.com

${ }^{\dagger}$ Equal contributors

${ }^{9}$ Department of Stomatology, Tongji Hospital, Tongji Medical College,

Huazhong University of Science and Technology, Wuhan, China

${ }^{10}$ Department of Neurosurgery, The second Affiliated Hospital of Guangzhou

Medical University, Guangzhou, China

Full list of author information is available at the end of the article
}

patient performance on three domains: activity level, ability to work, and ability of self-care. Evaluating the patient's ability to perform ordinary activities is rated on 11 levels. The total score ranged from $0=$ Dead to $100=$ Normal [4]. LGG progresses slowly, with the average survival period of 6 to 8 years. There are a lot of controversies about prognostic factors including age, pre-operative clinical manifestation, location of tumor, volume of tumor, and extent of resection in LGG. These studies did not explore the functional status of patients preoperatively and postoperatively. The goal of this study is to investigate the postoperative functional status variation of adult supratentorial superficial lowgrade glioma (ASS-LGG) to provide the surgical strategy. 


\section{Methods}

We collect the data of patients who underwent surgery and were pathologically diagnosed as LGG in our department from Jan. 2008 to Dec. 2010. The uniform table was used to collect data including pre- and postoperative KPS, age, gender, clinical manifestation, size and location of the tumor, the duration of symptom, degree of resection, and pathologic grade. The nonconditional logistic regression was used to assess the change of functional status and analyze the factors affecting functional status. KPS was implied to elevate the functional status of patients. The alteration of KPS beyond 10 points was considered as being valuable. SPSS software package version 18.0 (SPSS Inc., Chicago, IL) was implied in statistics.

\section{Results}

Of 112 adult patients proven with LGG surgically, 8 patients withdraw. In the rest 104 patients, the gender ratio (male/female) is $1: 1.7(38 / 66)$. The average age was 40 years old. The duration of symptom ranged from 1 week to 3 years (6 months in average). The average diameter of tumor was $5 \mathrm{~cm}$. The locations of tumor were frontal lobe $(31 \%)$, temple lobe $(36 \%)$, parietal lobe (12\%), occipital lobe (9\%), and multi-lobes (12\%). Fiftyseven patients' tumors were situated in the left cerebral hemisphere, 47 in the right side. The degree of resection depended on whether the tumor was seated in the functional area or not. The surgical principle was executed as follows: tumor located in the functional area-partial resection (13\%); near the functional area-subtotal resection (29\%); and the non-functional area-total resection (58\%). All patients acquired pathologic diagnosis: 44 (42\%) were grade I and 60 (58\%) were grade II. About $33 \%$ patients had combined radiological treatment following surgery.

The average KPS before surgery was 65 . We followed up all patients for 6 to 18 months; two patients died from complication (KPS $=0)$. The mean KPS after surgery was 75 . We found that four factors were associated with the postoperative functional status of patients (Table 1). They are age less than 40 years, the size of tumor less than $5 \mathrm{~cm}$ in diameter, tumor in the right hemisphere, and limited resection of tumor in the functional area. To patients over 40 years, their improvement of KPS was worse than the younger. Patients with the tumor's diameter less than $5 \mathrm{~cm}$ have better improvement of KPS than those more than $5 \mathrm{~cm}$. These patients in the right hemisphere LGG have better improvement after surgery. According to whether the tumor is located in the functional area, the patients' improvement of KPS shows a trend as follows: partial resection (functional area) > subtotal resection (near functional area) > total resection (non-functional area).
Table 1 The relativity between the functional status and the relevant factors

\begin{tabular}{llllll}
\hline Factors & $B$ & SE & $X^{2}$ & $p$ & $O R$ \\
\hline Gender & -0.183 & 0.166 & 1.213 & 0.271 & 0.833 \\
Age & -0.086 & 0.340 & 4.064 & $\mathbf{0 . 0 4 8}$ & 0.915 \\
Duration of symptom & 0.254 & 0.288 & 0.776 & 0.378 & 1.038 \\
Location & -0.242 & 0.310 & 0.607 & 0.436 & 0.624 \\
& 0.278 & 0.621 & 0.200 & 0.655 & 3.105 \\
& -0.227 & 0.573 & 0.157 & 0.692 & 1.850 \\
Size & 0.841 & 0.379 & 3.908 & 0.127 & 2.319 \\
Hemisphere & 0.540 & 0.349 & 2.390 & $\mathbf{0 . 0 3 8}$ & 1.716 \\
Resection degree & -0.224 & 0.304 & 4.542 & $\mathbf{0 . 0 2 0}$ & 0.799 \\
& -0.410 & 0.208 & 5.885 & $\mathbf{0 . 0 3 5}$ & 0.664 \\
Pathologic grade & -0.820 & 0.608 & 41.345 & 0.100 & 0.441 \\
Pre-KPS & 0.278 & 0.621 & 0.200 & 0.655 & 3.105 \\
\hline
\end{tabular}

Gender: (1) female; (2) male. Age: (1) < 40; (2) > 40. Duration of symptom: (1) $<6$ months; (2) > 6 months. Location: (0000) frontal lobe; (1000) parietal lobe; (0100) temple lobe; (0010) occipital lobe; (0001) multi-lobes. Size: $(1)<5 \mathrm{~cm}$; (2) $>5 \mathrm{~cm}$. Hemisphere: (1) left; (2) right. Resection: (00) total resection; (10) subtotal resection; (01) partial resection. Tumor pathologic grade: (1) WHO grade I; (2) WHO grade II. KPS: (1) $\geq 70$; (2) $<70$

\section{Discussion}

For ASS-LGG, there is still controversy on the appropriate management and impact factors for functional status, such as age, the duration of symptoms, the size and location of tumor, histology, surgical strategy, and adjuvant therapy. Age and pathologic grade were admitted as the impact factors [5, 6]. All of the practicable therapy can be selected for ASS-LGG, but there is no enough evidence to prove which the criteria is. We analyzed the ASS-LGG patients' data and compared their clinical characteristics in order to screen out the impact factors for functional status in ASS-LGG patients, which might provide some references for the patients' surgical strategy.

Some authors have observed that age is a determinant for prognosis: the younger the patient is, the better the prognosis is [6-9]. In our research, we focused on the change of KPS before and after surgical intervention, analyze the amelioration of functional status which the patients gain through surgery, and found that the improvement of KPS through surgery was better in age less than 40.

Tumor less than $5 \mathrm{~cm}$ in diameter have more favorable prognosis than more than $5 \mathrm{~cm}$. The volume of the tumor obviously increased the difficulty of surgery. However, even for those patients whose tumor sized less than $5 \mathrm{~cm}$ in diameter, the patients could not get significant improvement of functional status after surgery when their initial symptom was epilepsy. 
It was a negative prognostic factor for the tumor in the left hemisphere $[10,11]$. Because the left hemisphere is dominant sphere compared with right hemisphere and contains much connecting and projecting fibers, surgery might destroy the functional area and cause neurological deficits, which would absolutely decrease the patients' functional status $[7,12]$. The exact lobe of tumor distribution is not an impact factor [13]. We found that the patients with partial resection have better improvement of functional status if tumor just extrudes or partially infiltrates the functional area. But this did not cause difference in average improvement of KPS.

Surgery is the first option in the treatment of ASS-LGG until today [14]. But there is still controversy on whether extensive resection should be done [1, 2, 15-18]. In our study, for those whose tumor was located in the functional gyrus, the patients have better amelioration of KPS when a conservative resection was done. Therefore, a limited but safe resection is beneficial to confirm the histological diagnosis of ASS-LGG, relieve the burden of the tumor, and protect the function.

In our study, the duration of symptom was not the relative factor for improvement of functional status. Some potential risks existed in the delayed operation patients, such as the tumor developing into high grade, irreversible nerve injure, and intractable epilepsy [19-23]. But there have been no randomized trials to analyze the benefit of surgery in early stage and the patients' status $[24,25]$. The strategy of management is "waiting and observation" after a biopsy in many centers $[25,26]$.

Many centers are more likely to treat ASS-LGG with immediate postoperative radiation, especially for those whose surgery is partial resection or pathology is grade II $[27,28]$. Early postoperative radiotherapy seemed to postpone the time of progression of low-grade glioma [29, 30], but we did not find evidence to prove its effectiveness in the improvement of functional status.

\section{Conclusions}

This study was based on the postoperative functional status analysis, which was validated by postoperative KPS elevation. To ASS-LGG patients, predicting the functional status after surgery depends on the patients' age, size, location of the tumor, and extent of resection. Relieving the size of the tumor and acquiring the pathological diagnosis should be recommended instead of the en bloc resection in the functional area.

\section{Abbreviations}

ASS-LGG: Adult supratentorial superficial low-grade glioma; KPS: Karnofsky performance status; LGG: Low-grade glioma
Funding

Not applicable.

\section{Availability of data and materials}

The data during and/or analyzed during the current study are available from the corresponding authors.

\section{Authors' contributions}

All authors contributed to the paper. JZ, YSC, YPL, ZQZ, JML, and CCG drafted the manuscript. QYY, XLW, YHR, QM, WYL, LM, YQY, and SYX performed the data collection. YQY and SYX supervised the data collection and revised this article. All authors read and approved the final manuscript.

Ethics approval and consent to participate

This study was approved by the local ethic committee, and written informed consent was obtained from every participant.

\section{Consent for publication}

Not applicable.

\section{Competing interests}

The authors declare that they have no competing interests.

\section{Publisher's Note}

Springer Nature remains neutral with regard to jurisdictional claims in published maps and institutional affiliations.

\section{Author details}

'Department of Neurosurgery, State Key Laboratory of Oncology in South China, Sun Yat-sen University Cancer Center, Collaborative Innovation Center for Cancer Medicine, 651 Dong Feng East Road, Guangzhou 510060, China. ${ }^{2}$ Department of Neurosurgery, The First Affiliated Hospital of Nanchang University, Nanchang, Jiangxi, China. ${ }^{3}$ Department of Neurosurgery, Tumor Hospital Affiliated of Xinjiang Medical University, Xinshi District, Ürümqi, Xinjiang, China. ${ }^{4}$ Department of Neurosurgery, The First Affiliated Hospital of Guangzhou University of Traditional Chinese Medicine, Guangzhou, China. ${ }^{5}$ Department of General Surgery, Shang Jin Nan Fu Hospital, West China Hospital, Sichuan University, Cheng du, Sichuang, China. ${ }^{6}$ Department of Neurosurgery, Guangzhou Baiyun District People's Hospital, Guangzhou, China. ${ }^{7}$ Department of General Surgery, West China Hospital of Sichuan University, Cheng du, Sichuang, China. ${ }^{8}$ Department of Neurosurgery, Affiliated Hospital of Guiyang Medical College, Guiyang, Guizhou Province, China. ${ }^{9}$ Department of Stomatology, Tongji Hospital, Tongji Medical College, Huazhong University of Science and Technology, Wuhan, China.

${ }^{10}$ Department of Neurosurgery, The second Affiliated Hospital of Guangzhou Medical University, Guangzhou, China.

Received: 7 April 2017 Accepted: 20 August 2017

Published online: 17 October 2017

References

1. Abeloos L, Brotchi J, De witte O. Management of low-grade glioma: a retrospective study concerning 201 patients. Neurochirurgie. 2007;53(4):277-83.

2. Ahmadi R, Dictus C, Hartmann C, Zürn O, Edler L, Hartmann M, Combs S, Herold-Mende C, Wirtz CR, Unterberg A. Long-term status and survival of surgically treated supratentorial low-grade glioma in adult patients. Acta Neurochir. 2009;151(11):1359-65.

3. Keles GE, Lamborn KR, Berger MS. Low-grade hemispheric gliomas in adults: a critical review of extent of resection as a factor influencing status. J Neurosurg. 2001;95(5):735-45.

4. Friendlander AH, Ettinger RL. Karnofsky performance status scale. Spec Care Dentist. 2009;29(4):147-8.

5. Ringash J, O'Sullivan B, Bezjak A, Redelmeier DA. Interpreting clinically significant changes in patient-reported status. Cancer. 2007;110(1):196-202.

6. Vitek L, Rosenzweig MQ, Stolling S. Distress in patients with cancer: definition, assessment, and suggested interventions. Clin J Oncol Nurs. 2007:11(3):413-8.

7. Claus EB, Black PM. Survival rates and patterns of care for patients diagnosed with supratentorial low-grade gliomas: data from the SEER program, 1973-2001. Cancer. 2006;106(6):1358-63. 
8. Gnekow AK, Kortmann RD, Pietsch T, Emser A. Low grade chiasmatichypothalamic glioma-carboplatin and vincristine chemotherapy effectively defers radiotherapy within a comprehensive treatment strategy - report from the multicenter treatment study for children and adolescents with a low grade glioma-HIT-LGG 1996-of the Society of Pediatric Oncology and Hematology (GPOH). Klin Padiatr. 2004;10(6):331-42.

9. Kreth FW, Faist M, Grau S, Ostertag CB. Interstitial 1251 radiosurgery of supratentorial de novo WHO grade 2 astrocytoma and oligoastrocytoma in adults: long-term results and prognostic factors. Cancer. 2006;106(6):1372-81.

10. Arienti VM, Botturi A, Boiardi A, Broggi G, Collice M, Fariselli L, Zanni D, Botturi M. Adult brain low-grade astrocytomas: survival after surgery and radiotherapy. Neurol Sci. 2001;22(3):233-8.

11. Cavaliere R, Lopes MB, Schiff D. Low-grade gliomas: an update on pathology and therapy. Lancet Neurol. 2005;4(11):760-70.

12. Duffau H, Capelle L. Preferential brain locations of low-grade gliomas. Cancer. 2004;100(12):2622-6.

13. Eyre HJ, Crowley JJ, Townsend JJ, Eltringham JR, Morantz RA, Schulman SF, Quagliana JM, Al Sarraf M. A randomized trial of radiotherapy plus CCNU for incompletely resected low-grade gliomas: a southwest oncology group study. J Neurosurg. 1993;78(6):909-14.

14. Grier JT, Batchelor T. Low-grade gliomas in adults. Oncologist. 2006;11(6):681-93.

15. Gudinaviciene I, Pranys D, Juozaityte E. Impact of morphology and biology on the prognosis of patients with gliomas. Medicina (Kaunas). 2004;40(2):112-20.

16. Gustafsson M, Edvardsson T, Ahlstrom G. The relationship between function, quality of life and coping in patients with low-grade gliomas. Support Care Cancer. 2006;14(12):1205-12.

17. Guthrie BL, Laws ER Jr. Supratentorial low-grade gliomas. Neurosurg Clin N Am. 1990;1 (1):37-48

18. Karim AB, Maat B, Hatlevoll R, Menten J, Rutten EH, Thomas DG, Mascarenhas F, Horiot JC, Parvinen LM, van Reijn M, Jager JJ, Fabrini MG, van Alphen AM, Hamers HP, Gaspar L, Noordman E, Pierart M, van Glabbeke $M$. A randomized trial on dose-response in radiation therapy of low-grade cerebral glioma: European Organization for Research and Treatment of Cancer (EORTC) study 22844. Int J Radiat Oncol Biol Phys. 1996;36(3):549-56.

19. Kleihues P, Burger PC, Scheithauer BW. Histological typing of tumors of the central nervous system. Brain Pathol. 1993;3(3):255-68.

20. Kortmann RD, Jeremic B, Weller M, Lutterbach J, Paulsen F, Bamberg M. Immediate postoperative radiotherapy or "watch and wait" in the management of adult low-grade glioma? Strahlenther Onkol. 2004;180(7):408-18.

21. Leighton C, Fisher B, Bauman G, Depiero S, Stitt L, MacDonald D, Cairncross G. Supratentorial low-grade gliomas in adults: an analysis of prognostic factors and timing of radiation. J Clin Oncol. 1997:15(4):1294-301.

22. Leighton C, Fisher B, Macdonald D, Stitt L, Bauman G, Cairncross J. The dose-volume interaction in adult supratentorial low-grade glioma: higher radiation dose is beneficial among patients with partial resection. J NeuroOncol. 2007:82(2):165-70

23. Lote K, Egeland T, Hager B, Stenwig B, Skullerud K, Berg-Johnsen J, StormMathisen I, Hirschberg H. Survival, prognostic factors, and therapeutic efficacy in low-grade glioma: a retrospective study in 379 patients. J Clin Oncol. 1997;15(9):3129-40.

24. Louis DN, Ohgaki H, Wiestler OD, Cavenee WK, Burger PC, Jouvet A, Scheithauer BW, Kleihues P. The 2007 WHO classification of tumours of the central nervous system. Acta Neuropathol. 2007;114(2):97-109.

25. Mecdonald DR. Low-grade gliomas, mixed gliomas and oligodendrogliomas. Semin Oncol. 1994;21(2):236-48.

26. Rajan B, Pickuth D, Ashley S, Traish D, Monro P, Elyan S, Brada M. The management of histologically unverified presumed cerebral gliomas with radiotherapy. Int J Radiat Oncol Biol Phys. 1994;28(2):405-13.

27. Rosenfeld MR. Should radiotherapy for low-grade glioma be given immediately after surgery of at the time of progression? Nat Clin Pract Neurol. 2006;2(3):128-9.

28. Szeifert GT, Prasad D, Kamyrio T, Steiner M, Steiner LE. The role of the gamma knife in the management of cerebral astrocytomas. Prog Neurol Surg. 2007;20:150-63.

29. Walker DG, Kaye AH. Diagnosis and management of astrocytomas, oligodendrogliomas and mixed gliomas: a review. Austral Radiol. 2001;45(4): $472-82$

30. Wantanabe T, Katayama Y, Yoshino A, Komine C, Yokoyama T, Fukushinma T. Treatment of low-grade diffuse astrocytomas by surgery and human fibroblast interferon without radiation therapy. J Neuro-Oncol. 2003:61(2):171-6.

\section{Submit your next manuscript to BioMed Central and we will help you at every step:}

- We accept pre-submission inquiries

- Our selector tool helps you to find the most relevant journal

- We provide round the clock customer support

- Convenient online submission

- Thorough peer review

- Inclusion in PubMed and all major indexing services

- Maximum visibility for your research

Submit your manuscript at www.biomedcentral.com/submit
Biomed Central 